\title{
Future designs of tertiary dance education: Scanning the field for decolonizing potentials in a major change project at the Department for Dance Pedagogy at Stockholm University of the Arts
}

\author{
Tone Pernille Østern, ${ }^{1,2 \star}$ Camilla Reppen, ${ }^{2}$ Katarina Lion, ${ }^{2}$ \\ Katarina Lundmark ${ }^{2}$ and Elisabet Sjöstedt Edelholm ${ }^{2}$ \\ ${ }^{1}$ NTNU Norwegian University of Science and Technology, Norway; \\ ${ }^{2}$ Stockholm University of the Arts, Sweden
}

\begin{abstract}
This performative hybrid research and development project contributes knowledge about the decolonizing potentials and challenges that are articulated through an initial scanning of the dance pedagogical field as part of a large change project in tertiary dance education at the Department for Dance Pedagogy at Stockholm University of the Arts in Sweden. To do this scanning in a way that would promote collective learning, multiple perspective taking and creativity, we utilised design thinking. In total, 140 scan cards collected through the project were analysed. Both students and staff and other people in different parts of the world within the dance educational field created the scan cards. As a result, we suggest that the scanning of the field has pushed ourselves, the rest of the staff, students, and others into a process of collective learning, multiple perspective taking, and creativity, in which clear decolonizing potentials, as well as challenges to change are expressed.
\end{abstract}

Keywords: change project; collective thinking; decolonization; design thinking; tertiary dance education

Received: February, 2021; Accepted: September, 2021; Published: November, 2021

The aim of this study is to analyse a collaborative scanning of the dance pedagogical field as part of a project that aims at radically changing and restructuring the Bachelor's Programme in Dance Pedagogy at the Department of Dance Pedagogy

\footnotetext{
^Correspondence:Tone Pernille Østern, e-mail: tone.pernille.ostern@ntnu.no

(C) 2021 T. P. Østern, C. Reppen, K. Lion, K. Lundmark \& E. S. Edelholm. This is an Open Access article distributed under the terms of the Creative Commons Attribution 4.0 International License (https://creativecommons.org/licenses/BY/4.0/), allowing third parties to copy and redistribute the material in any medium or format and to remix, transform, and build upon the material for any purpose, even commercially, provided the original work is properly cited and states its license.

Citation: T. P. Østern, C. Reppen, K. Lion, K. Lundmark \& E. S. Edelholm. «Future designs of tertiary dance education: Scanning the field for decolonizing potentials in a major change project at the Department for Dance Pedagogy at Stockholm University of the Arts» fournal for Research in Arts and Sports Education, Special issue: Decolonizing perspectives of arts education, Vol. 5(4), 2021, 62 
(DDP) at Stockholm University of the Arts (Uniarts), Sweden. Our understanding is that tertiary dance education is in the process of a paradigm shift, dismantling ethnocentric practices and thinking. A predominant Euro-American perspective, permeating both the content and structure of tertiary dance education, has tended to push other ways of doing and thinking dance and dance pedagogy aside. This article builds on, and contributes to, the paradigm shift towards a notion of critical scrutiny of existing dance educational structures, diversity, inclusion and decolonization. We believe that the collective learning and multiple perspective taking we have experienced among ourselves and the staff involved at DDP through this process might be of interest to a broad dance educational field. In this article we ask: Which decolonizing potentials and challenges for future designs of tertiary dance education can be identified and created through a collaborative scanning for signals of change in the dance educational field?

In this article, we first present the context of the project, and then a selection of previous relevant research. We then continue with a section on methodology before defining decolonization through the chosen theoretical perspectives. Finally, we articulate the decolonizing potentials and challenges produced through the analysis, before discussing and concluding the article.

\section{Institutional, cultural and author context}

Despite growing diversity in the Swedish population and the legislated demand for broadened recruitment in tertiary education (Ministry of Education and Research, 1992) tertiary performing art and art schools in Sweden struggle with homogeneity (Dominquez \& Annerbom, 2015). At the time of writing this article, a majority of staff and students at DDP are white, and a large majority of staff and students are female. However, this does not reflect the current diversity in the Swedish population. In 2012 Hubinette et al. (2012, pp. 47-48) reported that 36.5\% of the Swedish population was born outside Sweden, and of them $10 \%$ have a non-European background. Diversity has increased since 2012. The Sami are the indigenous Swedish population, and their land Sápmi stretches across Norway, Sweden, Finland and Russia. The Sami people and culture have suffered from colonialisation by the majority populations in these four countries. The staff and students at DDP are thus by no means representative of the diverse population of Sweden today. This is again reflected throughout the department and the study programmes through a lack of diversity concerning the dance genres taught, the teaching pedagogies, curriculum, the choreographic tools utilised, and the artistic expressions at DDP.

During recent years several tertiary (performing) art institutions in Sweden have been heavily criticised for being permeated with structural racism (Dominquez \& Annerbom, 2015; Kallelid, 2021; Lind, 2020). It should be noted that criticism of the lack of context-specific indigenous perspectives like the Sami culture in (performing) arts institutions in Sweden is not emphasized in this public debate. However, 


\section{T. P. Østern et al.}

Sweden's abuse of the Sami in the 19th century is a painful and under-communicated part of Swedish colonialism and exoticisation of ethnic groups, also in the arts educational field. The Bachelor's Programme in Dance Pedagogy at DDP is no exception to this situation.

Since its founding in 1963 the programme has seen a number of organisational changes (Lilja \& Ståhle, 2013) and is today a part of the current organisational structure at Stockholm University of the Arts. ${ }^{1}$ Several efforts to diversify the student body and work towards greater inclusion have been made. These projects and efforts have, unfortunately, proved insufficient. In the academic year 2018/2019 students of the department voiced strong critique concerning conditions of white supremacy, structural racism in the curriculum content and structure, and lack of diversity in the department.

With this as a background, a change project was initiated by the Dean ${ }^{2}$ to scrutinise the content and structure of the BA Programme in Dance Pedagogy in order to unlearn and re-write how dance and dance pedagogy are understood and taught at the department. The homogeneous staff and student body and a curriculum that leans heavily on Euro-American perspectives and knowledge systems indicate a colonial and racist structure that the change project seeks to address. Continuous lack of diversity and ongoing colonial structures would simply be unethical, failing to make the BA Programme in Dance Pedagogy relevant for students of today, living in contemporary society. It would fail to prepare them for a multiculturally rich future needing $21^{\text {st }}$ century skills, democratization, equity, collaboration, and inclusion.

The five authors of this article constitute the project group, which in 2020 received a mandate from the Dean to design and facilitate the initial stages of a change project involving all employees at DDP. The representation among the authors is homogeneous: all are white women from a Nordic, middle-class and academic background. Further, all the authors except one are previous students at the department. We acknowledge that this is an indicator of the troublesome situation at the department with a homogeneous staff reflecting Euro-American perspectives and knowledge systems, and that this most probably will indicate bias in the project. The change project is slow and ongoing, and this article only reflects the first stage, consisting of scanning the field and looking for signals of change.

\section{Previous research}

The last decades have brought about major changes in higher education in dance worldwide. Dance research has contributed to an ongoing shift of focus from a

\footnotetext{
${ }^{1}$ The Department of Dance Pedagogy offers three programmes: a 3-year Bachelor degree, a 2-year Master's degree and a 5-year study programme in dance pedagogy, as well as independent study modules with different themes connected to dance pedagogy.

${ }^{2}$ The Dean at the time when this project started, and who initiated the change project through the scanning of the field, was Beata Alving.
} 
previously uncritical and colonial western canon towards more critical and inclusive dance practices in higher education, where the ideals of modernism have been critically explored and deconstructed with the help of post-colonial and decolonial theories.

Walker $(2017,2020)$ has extensively researched the current state of dance in higher education in a US context from a critical black aesthetics approach. She examined a large number of dance educational texts as well as conducted a cross-sectional study of nine dance departments in the US, critically exploring historically oppressive pedagogy within dance (Walker, 2020). Walker offers several suggestions for how tertiary dance education can move beyond the racist white supremacy space it finds itself in today (Walker, 2020). Davis (2018) critically discusses how the pervasive reach of whiteness affects dance education in American schools from P-12 through higher education. McCarthy-Brown (2014) describes how most dance departments in the US require rigorous study of traditional western dance forms and how that is common in western countries. Schupp and McCarthy-Brown (2018) see that few programmes position other dance genres at the same level as modern dance and ballet in their curricula, and many non-white students feel cultural diversity is not valued in their dance programmes (Schupp \& McCarthy-Brown, 2018). Schupp and $\mathrm{McC}$ arthy-Brown conclude that they see cultural diversity in tertiary dance programmes in the US, yet curricula and educational outcomes remain tied to western constructs of dance as art. Kerr-Berry (2018) argues that in order to challenge the white body's superiority in dance history courses the use of a critical race theory lens is required, emphasising that this lens counteracts whiteness as property when it comes to content and the right to exclude dance in practice as well as in aesthetics. Additionally, Oliver (2020), Horrigan (2020), Hagan (2029), and Bell (2020) are examples of the growing number of researchers and practitioners who call for action regarding the racist and racialised state that tertiary dance education finds itself in.

Mabingo (2015) focuses on the question of dance pedagogy in learning African dances. He argues that even though African dance forms have been included in American tertiary dance education to enhance artistic and cultural diversity, the instructional methodologies that are applied in teaching these dances are commonly founded on western pedagogic canons and thought. Cariño (2017) draws similar conclusions in a Singaporean context, presenting a study of how higher dance education in Singapore after 2000 changed towards offering dance from an Asian context, but still with choreographic tools drawn from western modern dance for choreography and education.

We have found no research literature that critically examines tertiary dance education from a decolonial perspective in a Nordic context. However, Østern (2016, 2017) investigated four study programmes in contemporary dance in Norway through a critical discourse analysis. Through student interviews, she found that authoritative teaching pedagogies were still active. We have also found no research literature on tertiary dance education from an indigenous perspective in a Nordic context, 


\section{T. P. Østern et al.}

and very little research on indigenous perspectives on dance in a Nordic context at all. However, one example is Hoppu (2020), who analysed how Skolt Saamis, living today under a threat of total assimilation to Finnish society, relate their dancing to the sense of belonging to a local Skolt community and claim agency for their own culture.

All in all, from previous research projects in and about tertiary dance education, it is evident that teaching dance and dance pedagogy at university level raises political and ethical questions regarding colonisation, power, and hierarchies. It is also evident that the whole field is in the midst of a large paradigmatic change. Not without struggle, the tertiary dance education field strives to shake up the strong links to dance from Euro-American traditions and modernistic aesthetics when it comes to education and choreography. In a Nordic context, there is an apparent lack of research literature on tertiary dance education from a decolonial and indigenous perspective, and the paradigm shift seems to have barely begun.

\section{A hybrid research and development project with a framework based on design-thinking}

The methodological frame for this study is a hybrid research and development approach, with an emphasis on change and development. We understand the hybrid research project as performative research (Arlander, 2018; Bolt, 2016; Haseman, 2006, 2010; Østern et al., 2021) through post-qualitative inquiry (St. Pierre, 2011, 2018). Performative research emphasises research as the creation of something new and the researcher position as one of entanglement with the research material, analysis, and knowledge production (Østern et al., 2021). As a research group, we have been on the inside of the practice in the change process: designing and carrying out the scanning and analysis in collaboration with colleagues, students, and others through a collaborative research approach (Savin-Baden \& Howell Major, 2013, p. 258). We have actively engaged with signals of change in the dance educational field through scanning of the field. Within a performative research paradigm, research and knowing do not occur at a distance, but through direct engagement with the world. Performative research further promotes a performative view on knowledge. This is in line with how Le Grange (2016, p. 10) emphasises the performative side of knowledge, and de-emphasises the representational side, as important for decolonialising tertiary dance education. Le Grange writes that:

A focus on the performative side of knowledge decentres (not destroys) dominant knowledge systems and produces third spaces (spaces in between) where seemingly disparate knowledge systems can be equitably compared and function to work together. (Le Grange, 2016, p. 10)

Within the umbrella of performative research and a performative view on knowledge, an essential methodological choice was to make use of design thinking, which "characterizes the mental processes that practitioners use as they frame, explore and re-frame ill-structured problems to derive design solutions" (Koh et al., 2015, p. v). 
To choose design thinking as an approach reflects the interest scholars have shown in developing education, and the ability that scholars and practitioners see in this approach to address complex issues, sometimes called 'wicked problems':

Wicked or ill-defined problems are problems that cannot be fully resolved in part because they cannot be fully comprehended. Wicked problems cannot be easily described or defined, and they can be changeable, shifting in nature over time. (Koh et al., 2015, pp. 2-3)

The challenges that are implied in the process of working with the BA Programme in Dance Pedagogy towards decolonization could be considered wicked problems. To understand how we, as an educational institution, contribute to the ongoing process of colonization, racialisation and epistemicide, and how we can address and resist structural racism in different ways is a complex issue that we need to address in this change process.

An example of how we have made use of design thinking is in the choice of process framework. According to the initial project plan from the Dean, the development of a new study programme was to be based on a landscape mapping of dance pedagogical practices in contemporary times. To carry out this mapping in a way that would promote collective learning, multiple perspective-taking and creativity we chose the Futures Design Framework developed by Bespoke Cph (Holsey Dyrman et al., 2018), which is based on interdisciplinary thinking and doing from design, strategic foresight, art, business, and the social sciences. This framework consists of four phases, which are called Situate, Search, Sense and Scale, respectively. The phases guided us through the process of defining the subject and scope of our search (Situate), mapping the landscape of our subject (dance pedagogical practices in contemporary times) by documenting signals of change on so-called scan cards (Search). A signal of change is a concrete and observable event that shows change and/or the potential for change. Scan cards are a way of collecting signals of change by documenting them on cards with an illustration, title, description, a reflection on the potential of the signal, and the sources from where the signal was picked up. An example of a scan card from the material is shown in Figure 1.

The scan cards were then clustered and analysed according to different principles to articulate connections and insights (Sense), which in turn will inform us on how to develop future scenarios, and, from these, try out a new Bachelor's Programme in Dance Pedagogy (Scale).

The making of a scan card is an act of interpretation: it is an interpretation of events, actions, behaviours, or values that one experiences in the world. Scan cards were created by students, staff, and other people within the dance educational field worldwide to make sure that we obtained more than our own interpretations of the world. The respondents outside of the institution were selected through staff and student networks and desktop research on dance education institutions. We assumed that the contacted respondents would want to participate in changing dance education, 
Figure 1. Example of scan card created during the project.
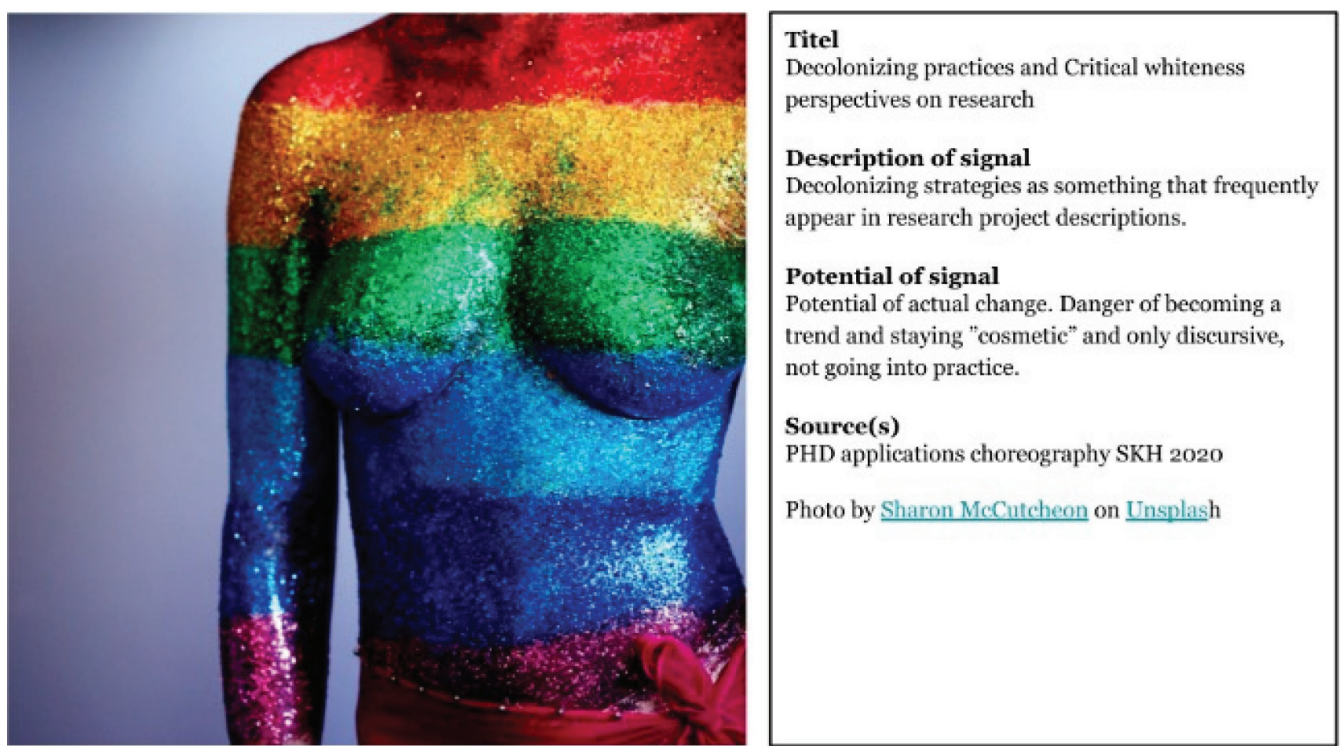

and we urged them to do so through the making of one or several scan cards. The creation of scan cards was done anonymously so there is no way of knowing how many of those invited created one or several scan cards. The invitation was sent out to about 300 people and/or organisations worldwide. All scan cards created were posted as pictures on an exposition on researchcatalogue.net (see Figure 2), the exposition platform for artistic research that Uniarts is connected to, and on a wall at the university campus for everyone to see how the mapping emerged and changed over time. In total, 140 scan cards were created.

This was a way to work collectively and creatively to draw up a map of where the respondents as a whole interpret dance pedagogical practice to be headed in the

Figure 2. A screen shot of the emerging exposition of scan cards at researchcatalogue.net.

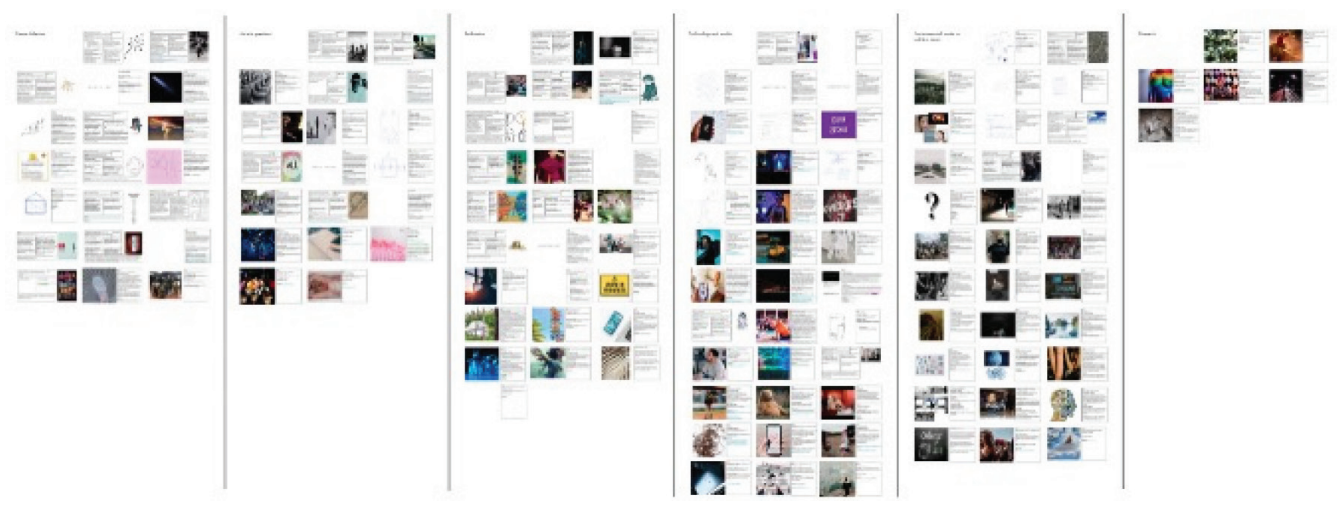


future, but we also consider the creation of scan cards as research material generated by multiple participants of a research process. Students, staff, and consultants on anti-racism ${ }^{3}$ engaged by Uniarts were later invited to analyse this collection according to different analysing principles. In addition to other principles, the scan cards were analysed for decolonizing potentials and challenges - which is the focus in this article. The analysis referred to in this article was made through sorting the scan cards with reference to the definition of decolonization described further down in this article.

There are several ethical issues to be considered in this change process and research project. The staff (our colleagues) at the department are research participants, as they contributed with creating scan cards, and we needed to inform them about writing this article before initiating it. The article was further made available for comment to all staff members before finalisation. In addition, a large number of dance educators from around the world participated in this research project through the contribution of scan cards. We made sure to inform the creators of scan cards about the purpose of the scanning, gave instructions about how to create scan cards, and informed them that the input might be part of research. Consent was given by the scan card creators that their participation could be the subject of research through the creation of a scan card; they were informed about this and encouraged not to write anything that could compromise their anonymity.

\section{Decolonizing potentials - an emerging definition}

As we took on the task of looking for decolonizing potentials, we needed to define what we mean by decolonization. This became clear to us as we started reading through all the scan cards. As we write this emerging definition, we follow what Le Grange (2016, p. 5) argues: "Decolonization is not an event but a process and it is not necessarily easy to achieve". There is disagreement about what decolonization means, and when it can be used (Stein \& Andreotti, 2016). Some might say that a group of authors like ourselves cannot use it, as we are representatives of a privileged part of society. However, we see that we need to work for decolonization anyway, as people in privileged positions need to be engaged in change processes: it is not only up to minoritised groups to mount the struggle for change. As we look for decolonizing potentials, we understand colonisation and racialisation as dimensions that are both social (shown, for example, in how colonial power is kept intact in social reproduction) and material (for example, the under-representation of non-white staff and students in universities). Social and material dimensions together create and stabilise colonial categories that are then used to stabilise unequal power relations. We see that

\footnotetext{
${ }^{3}$ The project group collaborates with Amphi, a knowledge organisation that supports others in working practically and strategically with inclusion, diversity, the prevention of violence and antiracism. See https://amphi.se/om/ Amphi was engaged by the Dean who started the change project to support it.
} 


\section{T. P. Østern et al.}

colonisation in higher education takes place through what is called epistemicide - the killing of knowledge systems (Hall \& Tandon, 2017):

Higher education systems today exclude many of the diverse knowledge systems in the world, including those of indigenous peoples and excluded racial groups, and those excluded on the basis of gender, class or sexuality. (Hall \& Tandon, 2017, p. 6)

Hand in hand with epistemicide comes the colonisation of curricula, another central area for decolonization to be pursued. Le Grange (2016) defines the curriculum as the stories we tell students about their past, present and future. Le Grange describes how deconstruction and decolonization of curriculum is about discarding what has been wrongly written about people's life experiences, negative labelling, deficit theorising, and culturally deficient models that have pathologised the colonised (Le Grange, 2016, p. 3, referring to Chilisa, 2012). To decolonize the curriculum, then, is about retelling the stories of the past and envisioning the future, Le Grange argues. As already mentioned, Le Grange (2016, p. 10) emphasises how a performative view on knowledge is important to allow for decolonialization.

As we look for the decentering of knowledge in our analysis of the scan cards, we trace any kind of suggestion that pushes traditional modernist knowledge with offshoots in Europe and North America even slightly out of the centre. As we search for signals of knowledge democracy, we look for invitations to non-western knowledge systems. As we look for performativity, we look for potentials that open for becomings and creations instead of representation and the stability of existing colonial structures. As we wonder about change expression in connection to the curriculum, we refer to Le Grange (2016, p. 7), who describes the explicit curriculum as the curriculum that the students are provided with, the hidden curriculum as what students implicitly learn about the dominant culture and its values, and the null curriculum as what is left out. As we look for signals of different efforts to decolonize, we attend to how three decolonizing responses are described by Stein \& Andreotti (2016, unpaginated). The first response is working for more diversity, the second is working for activism and structural change, whilst the last response implies a paradigm shift and major change: what we would see as decolonialization. What these potentials will lead to in terms of actual change in our BA Programme in Dance Pedagogy in a Swedish context, we still do not know, as this is the next step and still out of reach as we write this article.

\section{Analysis and articulation of potentials}

Based on the definition on decolonizing previously described, we now move on to the actual analysis of the 140 scan cards. As we investigate the scan cards with and through the definition of decolonization and decolonial concepts described, we have located a number of potentials and challenges. In the following we name and describe 
these potentials and challenges. The decolonizing potentials are not worked into the actual context at Uniarts here, as this is outside the scope of this article. Here, we merely seek to identify decolonizing potentials in the created scan cards as a step towards change-making that will prepare the ground for action in the BA Programme in Dance Pedagogy. ${ }^{4}$

\section{Decolonizing potentials}

A flexible and critical curriculum is a decolonizing potential as suggested by several of the scan cards. These focus on the course progress structure and rigid requirements for access to courses and programmes in higher education. These scan cards can be connected to the decentring of Euro-American knowledge as they critique what kind of experience and knowledge is considered a prerequisite to access different courses and programmes in higher education.

Dance as politics is a clear decolonizing potential, occurring frequently on the scan cards. This includes scan cards about how dance could be politics (not an art form), dance as activism, the agency of dance as a political discourse, and critical discussions on how dance, especially in dance education in an academic context, is still very much entrenched in exclusion and racism. Several of the scan cards reveal worries and anger about how racism as an extension of historical injustices, as well as how the exclusion of possible dancers, choreographers, and dance teachers with a range of different bodily abilities remain one of the largest problems within the dance field - especially so in academia. The potential of dance as politics compels critical questions to be asked: Who can become a dancer? Who can become a dance teacher through the academic system? Does the qualifying system for academic dance education function as a gatekeeper for critical renewal in the dance field? Could dance pedagogy have agency to radically change what is conceived as art? And what is the role of the dance teacher? Several scan cards highlight the different possibilities and responsibilities that dance artists and dance teachers of today and the future face in relation to political, social and environmental issues and changes. In this decolonizing potential we can see a call for dance teachers to take a more influential position in these issues; to become more involved in their respective communities and in wider society.

Pluralistic dance is a decolonizing potential that we locate among many of the scan cards provided. Pluralistic dance in terms of potential covers a range of ideas. Several scan card authors write about how a shrinking world is pushing more student

\footnotetext{
${ }^{4}$ During the process of writing this article, the change project has continued at DDP, with design principles for the new BA Programme being formulated based on these decolonizing potentials, and from there new learning goals have been formulated. As this article enters its final stages, new course descriptions are being written. However, this process is outside the scope of this article, which only focuses on the process of mapping the landscape and preparing for action though the scan cards process.
} 


\section{T. P. Østern et al.}

and staff diversity mobility around the world, entering one another's "places", emphasising the value of this dance (education) migration. Others draw attention to how "diversity is becoming the organising principle of the world we are living in" (quote on scan card). Several scan card authors argue for the relevance on the dance field to work through an ethics of plurality. One scan card author writes:

I experience a dissolve of (some) centralised locations of power over what constitutes our field - aesthetics, politics, the writing of history. Instead of ONE history/ technique/master, I see an abundance. The compulsion of our late capitalist, white supremacist, hetero-patriarchy is to acknowledge ONE (the genius, the original, the profitable). This inflicts violence on many, many, many others.

The potential for understanding dance as pluralistic dance without a hierarchy between different dance genres and expressions in favour of Euro-American traditions, is highly political and urges for major discursive, ideological, aesthetic, material and pedagogical change in the dance (education) field. The potential, if realised, might redistribute and reorganise what matters, and whose mattering is allowed to matter.

New spatialisations for dance is a decolonizing potential that we have located based on scan cards about digitalisation, access, sharing and mobility. Dance, having been so connected to a studio space or physical classroom, is in the digital era going through a paradigmatic shift regarding spatialisation. Dance possibilities are now spread out on a global digital network with no clear centre of gravity. This turns (colonial) traditions connected to access, teachers, genres, and class time upside down, and allows for online access, mobility, diversity, pluralistic dance genres, and learning at all times. Additionally, the topic of sharing is brought up on the scan cards, pushing towards this potential. Not only can digital spaces be shared in very different ways to the analogue studio, but also there is the idea of allowing dance to pop-up in multi-functional places shared by others for other activities, connecting dance less to a space, and more to a time and to people. The suggestion for new spatialisations for dance is also connected to professional change, as the dance teacher is becoming more of a community-oriented dance teacher, entering and taking part in creating ever new spaces compared to the classroom or studio-based teacher, decentering spaces and places that traditionally hold power for dance.

Non-white dance is a decolonizing potential that is revealed as some scan cards critique the curriculum of most dance education as being too white, and others focus specifically on dance genres other than ballet and contemporary dance. This collection of scan cards points towards a future in which a greater diversity of dance genres is made available as a major in dance education, and that it should be possible to get a BA in dance pedagogy without having to study white dance. There are also scan cards that emphasise the importance of changing the underlying principles of dance education, to not presuppose the perspectives and practices from Euro-American concert dance in teaching choreography, for 
example, and instead develop the ability to facilitate improvisation and choreography from within a genre. This would entail a significant shift in the explicit as well as the hidden curriculum.

The more-than-human body, implying a paradigm shift from the somatic, phenomenological and subjective body is a decolonizing potential that is only mentioned on a single scan card. Overall, there are very few scan cards that write about or problematise the body at all. This might be a challenge, but we still choose to see this one scan card, together with others writing about environmental concern and the possibility for dance to contribute to sustainable living on earth, as a decolonizing potential. This scan card author writes about how the impact of the word "somatics" has deeply influenced their view on the dancing body, but asks why we use this term now, arguing that

As time has passed, we have realised that our knowledge goes beyond the 'soma', the 'body'. We need to find and explore other descriptions that align with where our interests and the practice has evolved.

We see this as the opening of a decolonizing potential, that destabilises and decentres what is understood as a 'body' and as a 'dancing body', thereby deeply destabilising ideas about dance as art and pedagogy.

Transdisciplinary and cross-sectorial collaborations are written about on several scan cards. We locate this as a decolonizing potential in that it challenges and dissolves strict disciplinary borders and thereby also disciplinary hierarchies. Transdisciplinary and cross-sectorial collaborations force dance and dance pedagogy into a context, and into articulating how dance/pedagogy contributes to that context. One scan card author writes:

Knowledge can no longer be siloed in insular disciplines. The potential of transdisciplinarity is that the barriers between academic disciplines will be broken when it comes to research, teaching, curriculum and other forms of collaborations.

Both collaborations with other sectors, disciplines and other art forms are mentioned as the future way to go on several scan cards. The division of and specialisation of art forms into distinct art forms like music, dance and drama is a Euro-American approach, an idea that has influenced countries over the world through colonialism. In many cultures, art forms are seen much more as one big art form together. As one scan card author notes: "Dance is not an independent discipline. It belongs and even dissipates in the performing art field more and more". The separation between dance and music can be considered a post-modernist Euro-American perspective and categorisation. A decolonizing potential would be to acknowledge this and to make it possible to practice other understandings of music and dance, as part of the same phenomenon or practice. A shift like this would entail a major change in explicit, hidden and null curriculum. 


\section{T. P. Østern et al.}

Naming, referencing, and contextualising is a decolonizing potential that half a dozen scan cards call for. They express the need for a practice of situating, contextualising and describing the history of dance (teaching) practice and research. Through these scan cards different practices of cultural appropriation in different dance teaching situations are challenged, and several of the scan cards pinpoint the importance of contextualising the methods and materials used in both dance teaching and research. One scan card author writes:

An increasing emphasis is on situating research in history, traditions, the artistic and/ or pedagogical field. To name the specific perspective and position one speaks from. Also naming the things that can seem "neutral" (for example, white perspectives on art history that have had a tendency to be considered a "given" within western contemporary dance).

We interpret this as a potential to move from cultural appropriation to cultural appreciation, to develop greater awareness of positions and perspectives taken, and the choice of methods and practices to develop in the direction of a decentralisation of Euro-American knowledge.

\section{Challenges working against decolonization}

There is no clear border between potentials and challenges for decolonization, but we have divided with regards to how the scan card authors have written about these aspects. With this blurry border between potentials and challenges in mind, we have located the following aspects as challenges mentioned on the scan cards:

A conservative dance field works against decolonization, a couple of scan card authors mention. They write that there is a gap between the innovations strived for in tertiary dance education and what is asked for in the field: dance schools and studios, including dance teachers and parents, sometimes ask for what one scan card author calls "outdated dance educational practices". The scan card author further elaborates this conservatism, acknowledging that it is not easy to define what is conservative in dance, since this depends on your perspective and value grounding in dance. However, it has to do with what is asked for by pupils, parents and dance teachers in the field when it comes to dance genres, aesthetics in dance, teaching pedagogies, and learning goals.

Neoliberalism and the increasing costs of attending higher education is a challenge mentioned. A challenge expressed in some scan cards is the greater influence that neoliberalism and market logics have had in higher education recently. When going through a university education is becoming more and more expensive, the winners will be those already in privileged positions. This is a trend that resists decolonization and cements the values and position of Euro-American knowledge systems.

The structural racism and racial injustices themselves that are far-reaching and deeply rooted in academia are recognised as a serious challenge to decolonization. The structural racism might be so imbued in our everyday lives in higher 
education that we might be blind to them entirely at different points through our process of trying to decolonize our practices, approaches, and structures. This struggle might be especially challenging due to its evasive nature. However, the other side of this struggle has a more explicit nature. This might seem obvious, but it is still worth mentioning that not all are keen on decolonization and anti-racist change. This is, of course, something to be prepared to face on different levels in a change project like this one.

In addition, we wish to mention the absence of a focus on Nordic indigenous and other minority cultures on the scan cards. It is striking that no one mentions Sami perspectives on the scan cards, although we guess there is a majority of scan card authors from the Nordic region. This also goes for us as project group members: we have not been sufficiently attentive towards signals of change concerning context-specific indigenous rights and perspectives. This, we see as a challenge for decolonization in a Swedish context.

\section{Designing collaborative in-between spaces for performative knowledge in tertiary dance education}

Higher education has been, and continues to be, a central site for continuous colonisation. Universities in the Nordic countries subscribe to the dominant western university model which favours the modernist western knowledge system, claiming this epistemology to be universal, and further that the western knowledge system is relevant and valuable universally.

In this performative hybrid research and development project we have analysed 140 scan cards designed through a collaborative scanning of the dance educational field for signals of change. Through this initial scanning, we have emphasised the performative side of knowledge, and de-emphasised the representational side, which Le Grange (2016, p. 10) writes is essential in a process of decolonizing the curriculum. As we have acknowledged knowledge as performative and invited participants to express signals of change, the scanning process has contributed ideas upon which action towards decentring dominant knowledge systems and producing spaces for other and alternative perspectives in between can be pursued (see also Le Grange, 2016). We might connect this process of decolonizing to the wicked problems that design-thinking seeks to grapple with (Koh et al., 2015, pp. 2-3). It is impossible to fully grasp all the nuances, aspects and consequences of the modernist, western knowledge system's grip on the field of dance education, as it is so normalised in each and every respect. However, we argue that the way this scanning project is designed has opened a space for creative reflection through the scan cards, which might have taken some small steps towards more inclusive understandings.

Our analysis reveals signals on the scan cards opening up for change processes towards a performative knowledge view, a decentring of Euro-American knowledge/ knowledge systems, knowledge democracy, and transformation enacted through 


\section{T. P. Østern et al.}

diverse efforts to resist colonisation, racialisation and epistemicide. This is materialised on the scan cards through suggestions, articulations, actions, ideas and visions that disturb and shake up taken-for-granted tendencies towards organisational structures, working methods, curriculum, knowledge systems, research methodologies, stories, language and theories, staff and student representation, and space expropriation entrenched within a "Modern/Colonial, Capitalist/Patriarchal, Western-centric/ Christian-centric World-system" (Grosfoguel, 2012, as cited in Stein \& Andreotti, 2016, unpaginated). An alarming challenge is that Nordic indigenous perspectives are absent from the scan cards.

We understand the act of looking for and articulating such decolonizing potentials, also identifying the struggles and challenges that cause violence to such potentials, as moving towards a performative knowledge view. This emphasises how knowledge and knowledge systems are value-laden sites of power that need to be in constant inbecoming and re-articulation, allowing for decolonization to happen. We suggest that the process of going through the initial phase of this change project, with an emphasis on change and development, has resulted in a portfolio of scan cards that underline the paradigmatic steps that need to be taken in the design of the new BA Programme in Dance Pedagogy. There are clear decolonizing signals of change and potentials for change needed, and urgently asked for, but the scan cards also show blindness towards decolonization in a way that includes Nordic indigenous perspectives. The scanning of the field has pushed ourselves, the rest of the staff, students, and others into a process of collective learning, multiple perspective taking and creativity, all of which we suggest are needed in order to eventually develop future scenarios and, from these, design and try out a new Bachelor's Programme in Dance Pedagogy. However, this process of learning and unlearning needs to continue, and also include turning our gaze towards the uncomfortable fact that indigenous perspectives in a Nordic context are not present in the mapping of signals for change that we have performed.

\section{Author biography}

Tone Pernille Ostern with a Doctor of Arts in Dance from the Theatre Academy, University of the Arts Helsinki, and a Professor in Arts Education with a focus on Dance at NTNU Norwegian University of Science and Technology. She also holds a position as Visiting Professor in Dance Education in Contemporary Contexts at Stockholm University of the Arts.

Camilla Reppen is Assistant Lecturer in Dance Pedagogy and project leader at Stockholm University of the Arts with a BA in Dance Pedagogy and MA in Educational Management. As artist/researcher/teacher she shows a particular interest in choreography as an approach to learning and decentralized perspectives on leadership practice in artistic processes. 
Katarina Lion is a researcher in intercultural theory. She has a $\mathrm{PhD}$ in Dance Theory from the Theatre Department at the University of Stockholm. Lion is Assistant Professor in Dance Theory at Stockholm's University of the Arts where she is responsible for courses in scientific methods, culture and art connected to dance historiography as well as courses in community art at the department of dance pedagogy.

Katarina Lundmark is Assistant Professor in Jazz dance at Stockholm University of the Arts, Sweden. She holds a BA in Dance Pedagogy and a Master in Contemporary Dance Didactics. She works mainly at the Institution for Dance Pedagogy. Katarina works regularly as a guest teacher at higher educations around Europe. Her educational focus is a contemporary approach to jazz dance as a field of knowledge, practice and art that is educationally and artistically diverse and non-normative.

Elisabet Sjöstedt Edelholm holds a B.A. in Dance Pedagogy and a B.A. in Education and has further education in dance from New York University and Norhern Colorado University. She is Assistant Professor in Children and Youth Dance at Stockholm University of the Arts, Sweden, where she has 40 years of teaching practice. Her focus is on creative dance for children, and ballet.

\section{References}

Arlander, A. (2018). Multiple futures of performance as research? In A. Arlander, B. Barton, M. Dreyer-Lude \& B. Spatz (Eds.), Performance as research. Knowledge, methods, impact (pp. 333-349). Routledge.

Bell, A. (2020). Critical living: Collapsing the distance between buzz words and practiced beliefs. Fournal of Dance Education, 20(3), 114-114. https://doi.org/10.1080/15290824.2020.1721504

Bolt, B. (2016). Artistic research: A performative paradigm? Parse 03 Issue Repetitions and Reneges, 3, $129-142$.

Cariño, C. (2017). Creating contemporary Asian dance in tertiary dance education: Research-based choreography at Nanynag Academy of Fine Arts. In G. Barton \& E. Baguley (Eds), The Palgrave handbook of global arts education (pp. 259-273). Palgrave Macmillan.

Chilisa, B. (2012). Indigenous research methodologies. Sage publications.

Davis, C. U. (2018) Laying new ground. Uprooting white privilege and planting seeds of equity and inclusivity. Fournal of Dance Education,18(3), 120-125. https://doi.org/10.1080/15290824.2018.1481965

Dominguez, E., \& Annerbom, E. (2015) Konstvärlden är fylld av koloniala föreställningar, strukturell diskriminering och klassförtryck. [An arts world full of colonial preceptions, systemic discriminaiton and class oppression]. Folkrörelsernas Konstfrämjande.

Grosfoguel, R. (2012). The dilemmas of ethnic studies in the United States: Between liberal multiculturalism, identity politics, disciplinary colonization, and decolonial epistemologies. Human Architecture: Fournal of the Sociology of Self-Knowledge, 10(1), 81-90.

Hall, B.L., \& Tandon, R. (2017). Decolonization of knowledge, epistemicide, participatory research and higher education. Research for All, 1(1), 6-19. https://doi.org/10.18546/RFA.01.1.02

Haseman, B. (2006). A manifesto for performative research. Media International Australia Incorporating Culture and Policy: Quarterly fournal of Media Research and Resources, 118 (February), 98-106.

Haseman, B. (2010). Rupture and recognition. Identifying the performative research paradigm. In E. Barrett \& B. Bolt (Eds), Practice as research - approaches to creative arts inquiry (pp. 147-157). Bloomsbury.

Hagan, C. (2020) Illuminating diverse voices in dance education. Fournal of Dance Education, 20(3), 115-120. https://doi.org/10.1080/15290824.2020.1772975

Holsey Dyrman, M., Winther Bjerregaard, C., Arroyo, N., Toldam, R., Liukkonen, M., Pavuk, A., \& Korntved Mortensen, A. (2018). Book of futures. Bespoke. 


\section{T. P. Østern et al.}

Hoppu, P. (2020). Dancing agency. Skolt Saami identities in transition. PULS fournal for Ethnomusicology and Ethnochoreology, 5, 26-44.

Horrigan, K. (2020). Welcoming in dancers from all traditions. Fournal of Dance Education, 20(3), $142-147$. https://doi.org/10.1080/15290824.2020.1789147

Hubinette, T., Hörnfeldt, H., Farahani, F., \& Rosales, R. L. (2012). Om ras och vithet i ett samtida Sverige. [About race and whiteness in contemporary Sweden]. Mångkulturellt Centrum.

Kerr-Berry, J. (2018). Counterstorytelling in concert dance history pedagogy: Challenging the white dancing body. In A. Kraehe, R. Gaztambide-Fernández \& S.B. Carpenter (Eds.), The Palgrave handbook of race and arts in education (pp. 137-155). Palgrave Macmillan.

Kallelid, M. (2021, February 10). Ansatte bedrev hærverk, og studenter blir kalt meningspoliti. Men den avgåtte rektoren forsvarer rasismeoppgiøret. [Employees committed vandalism, and students were called the opinion police. But the resigned cancellor defends the racism upriots]. Aftenposten, unpaginated. https://www.aftenposten.no/kultur/i/lE4pLe/ansatte-bedrev-haerverk-og-studenter-blir-kalt-meningspolitimen-den

Koh, J. H. L., Chai, C. S., Wong, B., \& Hong, H-Y. (2015). Design thinking for education conceptions and applications in teaching and learning. Springer.

Lind, K. (2020, December 29). Polariserade debatter om rasism på nordiska konsthögskolor. [Polarized debates about racism at Nordic art academies]. Kulturnytt $i$ P1, Sveriges radio. https://sverigesradio.se/ artikel/7633914

Le Grange, L. (2016). Decolonizing the university curriculum. South African fournal of Higher Education, 30(2), unpaginated.

Lilja, E., \& Ståhle, A. K. (2013). DOCH 1963-2013. Dans och Cirkushögskolan.

Mabingo, A. (2015). Decolonizing dance pedagogy. Fournal of Dance Education, 15(4), 131-141.

McCarthy-Brown, N. (2014). Decolonizing dance curriculum in higher education: One credit at a time. Fournal of Dance Education, 14(2), 125-129.

Ministry of Education and Research. (1992). The Swedish Higher Education Act (SFS 1992:1434). https://www. riksdagen.se/sv/dokument-lagar/dokument/svensk-forfattningssamling/hogskolelag-19921434_sfs-19921434

Oliver, W. (2020). Race and Racism. Fournal of Dance Education, 20(3), 109-111. https://doi.org/10.1080/1529 0824.2020 .1793620

Østern, T. P., Jusslin, S., Nødtvedt Knudsen, K., Maapalo, P., \& Bjørkøy, I. (2021). A performative paradigm for post-qualitative inquiry. Qualitative Research, 1-18. https://doi.org/10.1177/14687941211027444

Østern, T. P. (2016). Oppdragelse til nikkedukkedanser eller dansekunstner? Hegemoni, diversitet og motstand i norske samtidsdansutdanningers dansefaglige forståelser. [Becoming a marionette dancer or dance artist? Hegemony, diversity and resistance in Norwegian tertiary contemporary dance education institutions' dance educational understandings]. In S. Øverås Svendal (Ed.), Bevegelser - norsk dansekunst $i 20$ år [Movements - Norwegian dance art for 20 years] (pp. 207-307). Skald forlag.

Østern, T. P. (2017). Norske samtidsdansutdanninger i spennet mellom modernisme og postmodernisme tidligere dansestudenters refleksjoner over påvirkningen av en danseutdanning. [Norwegian tertiary dance education institutions in-between modernism and post-modernism - previous dance students' reflections about the influences from their dance training]. På Spissen forskning, 3(2), 1-23. http://dx.doi. org/10.18862/ps.2017.302

Savin-Baden, M., \& Howell Major, C. (2013). Qualitative research - the essential guide to theory and practice. Routledge.

Schupp, K., \& Mcarthy-Brown, N. (2018). Dancing with diversity: Students' perceptions of diversity in postsecondary dance programs. Dance: Current Selected Research, 9, 1-21.

Stein, S., \& Andreotti, V. D. O. (2016). Decolonization and higher education. In M. Peters (Ed.), Encyclopedia of educational philosophy and theory, unpaginated. Springer. https://doi.org/10.1007/978-981-287-5327_479-1

St. Pierre, E. A. (2011) Post qualitative research: The critique and the coming after. In N. K. Denzin, \& Y. S. Lincoln (Eds.), The SAGE handbook of qualitative inquiry (pp. 611-635). Sage Publications.

St. Pierre, E. A. (2018). Writing post qualitative inquiry. Qualitative Inquiry 24(9), 603-608. https://doi.org/ $10.1177 / 1077800417734567$

Walker, L. L. A. (2017). Towards enturcultural engaged pedagogy: Revisioning curricula in university dance studies from a black dance aesthetics approach [Doctoral dissertation]. University of California.

Walker, A. (2020).Traditional white spaces. Fournal of Dance Education, 20(3), 157-167. https://doi.org/10.1080/ 15290824.2020 .1795179 